The Texas Medical Center Library

DigitalCommons@TMC

The University of Texas MD Anderson Cancer Center UTHealth Graduate School of

Biomedical Sciences Dissertations and Theses

(Open Access)
The University of Texas MD Anderson Cancer

Center UTHealth Graduate School of

Biomedical Sciences

\title{
$5-2014$
}

\section{Support Desired by Women Following Termination of Pregnancy for a Fetal Anomaly}

\author{
Aarti Ramdaney
}

Follow this and additional works at: https://digitalcommons.library.tmc.edu/utgsbs_dissertations

Part of the Obstetrics and Gynecology Commons, and the Other Medical Specialties Commons

\section{Recommended Citation}

Ramdaney, Aarti, "Support Desired by Women Following Termination of Pregnancy for a Fetal Anomaly" (2014). The University of Texas MD Anderson Cancer Center UTHealth Graduate School of Biomedical Sciences Dissertations and Theses (Open Access). 452.

https://digitalcommons.library.tmc.edu/utgsbs_dissertations/452

This Thesis (MS) is brought to you for free and open access by the The University of Texas MD Anderson Cancer Center UTHealth Graduate School of Biomedical Sciences at DigitalCommons@TMC. It has been accepted for inclusion in The University of Texas MD Anderson Cancer Center UTHealth Graduate School of Biomedical Sciences Dissertations and Theses (Open Access) by an authorized administrator of DigitalCommons@TMC. For more information, please contact digitalcommons@library.tmc.edu.

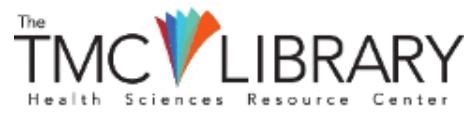




\title{
SUPPORT DESIRED BY WOMEN FOLLOWING TERMINATION OF PREGNANCY \\ FOR A FETAL ANOMALY
}

\author{
A \\ THESIS \\ Presented to the Faculty of \\ The University of Texas \\ Health Science Center at Houston \\ and \\ The University of Texas \\ MD Anderson Cancer Center \\ Graduate School of Biomedical Sciences \\ in Partial Fulfillment \\ of the Requirements \\ for the Degree of \\ MASTER OF SCIENCE
}

by

Aarti Ramdaney, BS

Houston, Texas

May 2014 


\section{Acknowledgements}

We would like to thank all of our study participants for their time, especially at such a sensitive and perhaps painful period in their lives. Additionally, we would like to thank the private Houston clinic for allowing us to survey their patients. Many patients expressed their gratitude in the clinic's professional and compassionate manner in providing such services. We would also like to thank the National Society of Genetic Counselors (NSGC) Prenatal Special Interest Group for providing funding for this study. 


\title{
SUPPORT DESIRED BY WOMEN FOLLOWING TERMINATION OF PREGNANCY \\ FOR A FETAL ANOMALY
}

\author{
Aarti Ramdaney, BS
}

With the rapidly evolving field of prenatal testing, there is a growing need to provide support for women pursuing a termination of pregnancy following the discovery of a fetal anomaly. Previous studies have documented that women in this situation often feel unsupported after the procedure, but the type of resources desired by this population remains undetermined. A longitudinal study was performed in 51 women terminating for a fetal anomaly at a private clinic at the time of the procedure, at 6 weeks, and at 3 months following the event. Surveys were kept anonymous and investigated the awareness and utilization of support resources as well as influential and preventative factors. Though largely knowledgeable of the existing resources, only 50\% admitted contemplating their individualized need for support. Anonymity, ease of access, and the desire to meet others in a similar situation online were commonly selected as the most influential factors in the decision to participate in support systems. Regardless, most women expected to rely on the support from family and friends. Only four respondents expressed that a lack of support from family and friends would influence them to pursue other support resources.

Additionally, 50\% expressed the desire to commemorate the pregnancy, though none wanted direct contact with their healthcare provider(s). The desire to move on from the pregnancy was the most cited factor that prevented consideration of support resources in the follow-up 
period and seemed more important to this population than other influential factors.

However, many women indicated not coping as expected and were unprepared for the psychological consequences following the procedure. Our findings indicate that women in these situations may not realize what their long-term support needs will be. Additional support resources that promote a flexible timeframe for uptake need to be developed to meet the unique desires of this population. 


\section{Table of Contents}

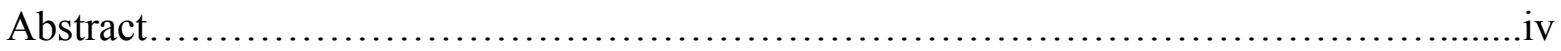

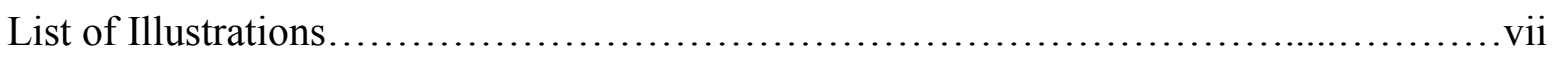

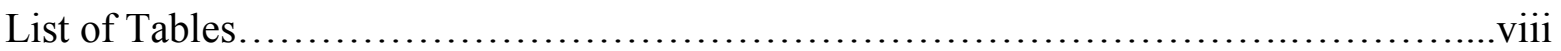

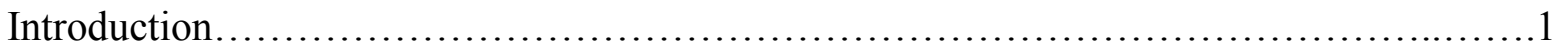

Materials and Methods.............................................................

Results.......................................................................

Discussion.................................................................. 13

Appendices

Appendix A: Letter of Invitation....................................... 18

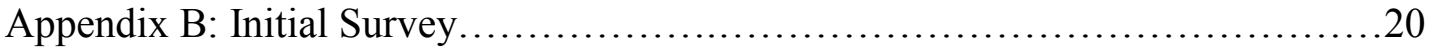

Appendix C: Follow-up Surveys.......................................22

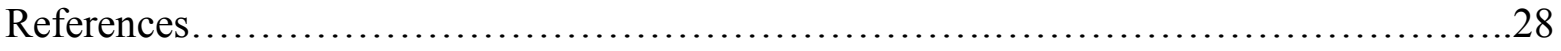

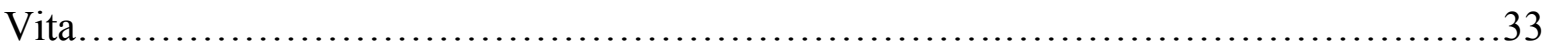




\section{List of Illustrations}

Figure 1. Flow chart of participant recruitment....................................4

Figure 2. Anomalies identified in the 51 pregnancies...............................

Figure 3. Participant reports on hardest factors in decision to end pregnancy...............9

Figure 4. Participants reports on factors that would most influence utilization of a support

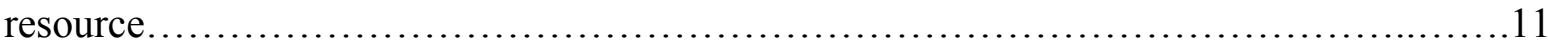




\section{List of Tables}

Table 1. Demographic information of 51 study participants of initial survey...............6

Table 2. Pregnancy information of study participants of initial survey $\ldots \ldots \ldots \ldots \ldots \ldots \ldots . . . \ldots 7$ 


\section{Introduction}

According to the Center for Disease Control, over 765,000 terminations were performed in the United States in 2010. Approximately $10 \%$ of these procedures took place in Texas (Pazol et al., 2013). Although the majority of terminations are performed on unplanned or unwanted pregnancies, studies estimate that approximately $5 \%$ of terminations are performed on intended pregnancies, including those performed for maternal indications and fetal anomalies (Finer et al., 2011). Although variable between timing of diagnosis and type of fetal anomaly, the majority of pregnancies with an identified severe fetal anomaly are reportedly terminated (Salveson et al., 1997; Mansfield et al., 1999; Schechtman et al., 2002; Souka et al., 2010).

Unlike other perinatal losses, parents undergoing termination of pregnancy for a fetal anomaly must make the active choice to end the pregnancy. This voluntary decision often puts these patients in a gray area between the categories of miscarriage/stillbirth/neonatal death and elective termination for social reasons. Termination is still considered a controversial issue in society, though most of the controversy lies within elective terminations for social reasons. Terminations for a fetal anomaly are considered to be rare and thus there is little societal understanding of the factors that may influence the termination of a wanted pregnancy (Kolker et al., 1993; Bryar, 2006). In a study done by Hunt et al. in 2009, the majority of pregnant couples who were faced with the decision to terminate in light of a fetal anomaly reported that they never anticipated making such a decision and felt wholly unprepared.

Even if the choice to terminate a pregnancy is made by a pregnant woman or pregnant couple as the best option for the given situation, psychological consequences may follow. 
Previous studies have explored these consequences and have found that grief, posttraumatic stress and depression are common responses (Elder et al., 1991; Kersting et al., 2009; Kersting et al., 2012). Almost all studies have found evidence of these responses, particularly grief, in the first few weeks and months following the procedure.

Long-term studies have been inconsistent. Several studies report that overall psychological distress may not decrease in the first few years after the event while others imply that the psychological distress does decrease within this time frame (Salveson et al., 1997; Kersting et al., 2005; Korenromp et al., 2005). In a longitudinal study by Korenromp et al. (2009) that started at four months following the termination procedure, it was determined that poor psychological response at that initial timepoint was the most important predictor of the long-term outcome. Additional risk factors contributing to the likelihood and duration of these consequences include quality of partner support, doubt of the diagnosis/severity of the condition, religious ties, maternal age and level of education (Korenromp et al., 1992; Korenromp et al., 2005; Kersting et al., 2012). Furthermore, though these consequences have been largely reported in mothers, psychological distress has also been reported among fathers (Korenromp et al., 2005; Robson, 2002).

Although psychosocial consequences following a termination of pregnancy procedure have been well documented, the type of psychosocial support desired by a patient experiencing a termination of pregnancy for a fetal anomaly has not yet been determined. Several support systems and resources exist for this patient population, such as websites, books, and support groups, but many are not updated regularly or may not be meeting the needs and wants of these patients. Recent studies have further explored the coping mechanisms of this population. In a study done by Lafarge et al. in the United Kingdom 
(2013), many women who had undergone a termination of pregnancy for a fetal anomaly reported feeling unsupported post-termination and expressed need for further resources. It is important to note that most studies exploring these coping mechanisms have gathered participants from pre-existing support groups and thus may represent a selection-bias. To our knowledge, a longitudinal study has not yet been done on the needs of this population beginning with the actual procedure date.

Our study aim was to identify what support, if any, women desire following a termination of pregnancy for a fetal anomaly, as well as if the support needed changes as time passes. Our study also investigated the support and resources utilized by these women and how they identified those support systems. The information collected will hopefully allow healthcare professionals to improve care and support for patients undergoing termination of pregnancy for fetal anomalies.

\section{Materials and Methods}

Human subjects approval was obtained through the University of Texas Health Science Center at Houston Institutional Review Board (Approval \#HSC-MS-13-0478)

\section{Participants and Survey Distribution}

The study population consisted of English- and Spanish-speaking women over the age of 18 years proceeding with termination of pregnancy for a fetal anomaly at a private Houston area clinic. The nurse at this private clinic gave a packet composed of a letter and initial survey to each patient. The letter served as the informed consent and patients who met the eligibility criteria were invited to complete the initial survey (a paper hardcopy) on the first day of the procedure (Time 0, T0; Figure 1). The initial survey asked participants about 
the support they had

been offered and the

support they wish they

had been offered, as

well as collected

relevant demographic

and pregnancy-related

information. The

packet also included

the option for each

participant to provide

contact information if

they wished to receive

follow-up surveys.

Time 0, T0: First day of termination

procedure

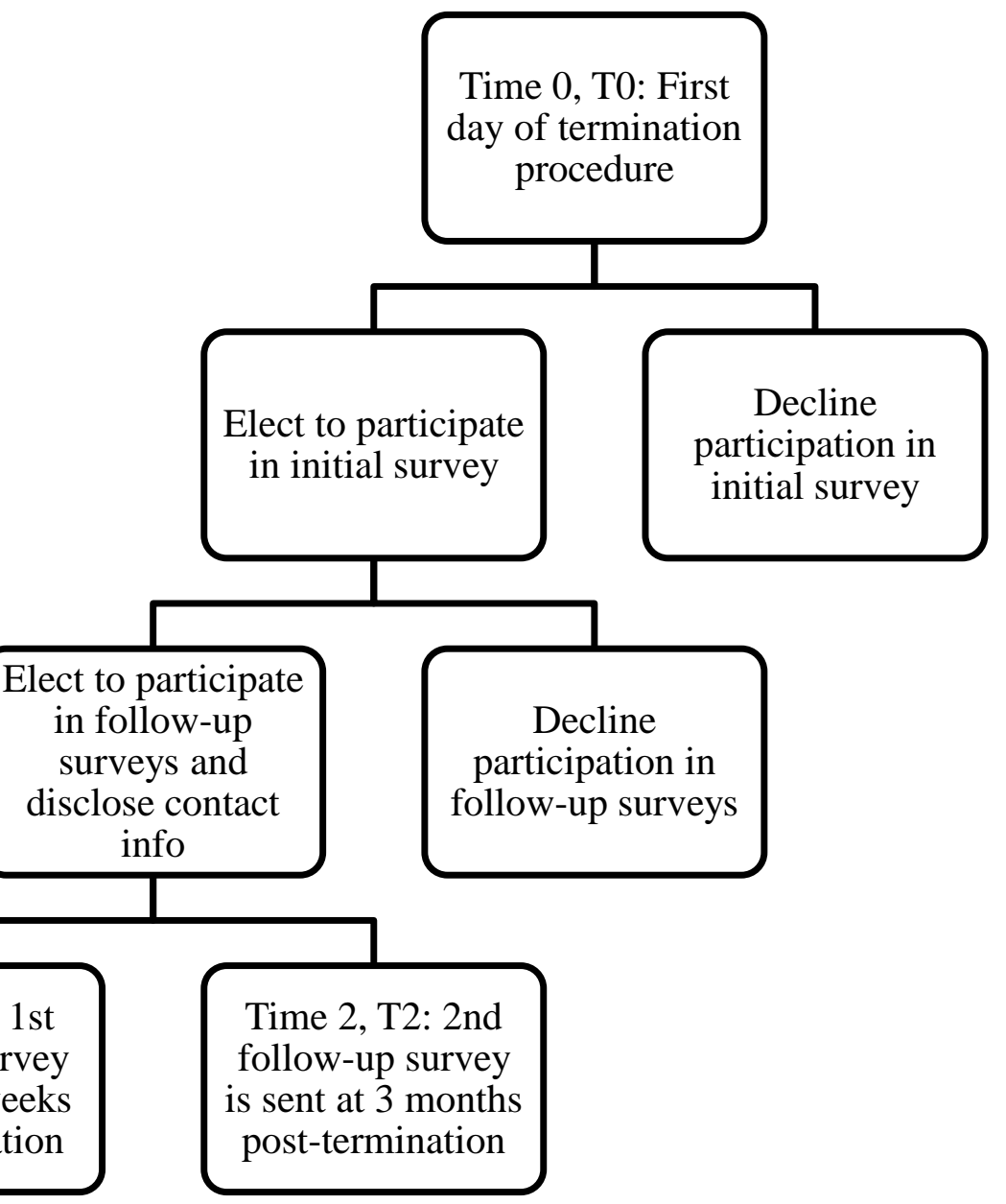

If contact

Figure 1. Flow chart of participant recruitment

information was

provided, two follow-up surveys were administered via email to the participant. The first follow-up survey was sent out 6 weeks following the termination procedure (Time 1, T1)

and the second was sent 3 months following the procedure (Time 2, T2). The follow-up surveys asked each patient what support she had utilized since her termination of pregnancy procedure and if her need or desire for support had changed since the initial or previous survey. Demographic and pregnancy-related information was also gathered with the followup surveys. Follow-up surveys were not linked to the initial or previous survey. 
Recruitment for this study was from September 16, 2013 to March 5, 2014 and followup surveys were administered through June 5, 2014.

\section{Data Analysis}

Data obtained from the surveys were entered into a secure database. Data analysis was performed using STATA (v.13, College Station, TX). Categorical variables were reported as frequencies and percentages. Continuous variables were reported as mean and standard deviation (sd) or median and interquartile range (IQR) for normally distributed and nonnormally distributed data, respectively. Contingency tests were used to compare categorical variables. Continuous variables were assessed using two-tailed parametric (t-tests) or nonparametric (Mann-Whitney tests) tests, for normal and non-normal data distributions, respectively. Statistical significance was assumed at a $\mathrm{p}<0.05$. For more qualitative data, common themes were identified.

\section{Results}

A total of 51 initial surveys were completed and with the exception of one survey in Spanish, all of the surveys were collected in English. The average age of the participants was $32.29 \pm 6.25$ years old and ranged from 18 to 45 years of age. Participants were most often Caucasian (62.8\%), Hispanic (15.7\%), or African American (11.8\%). The majority of the respondents had at least some college experience $(83.7 \%)$, with over half reporting a college degree or higher (67.4\%). Respondents mainly identified themselves as Christian $(49.0 \%)$ or Catholic $(17.7 \%)$, though there were participants of the Muslim (5.9\%) and Buddhist (2.0\%) faiths. Please see Table 1 for participant demographics. 
Table 1. Demographic information of 51 study participants of initial survey

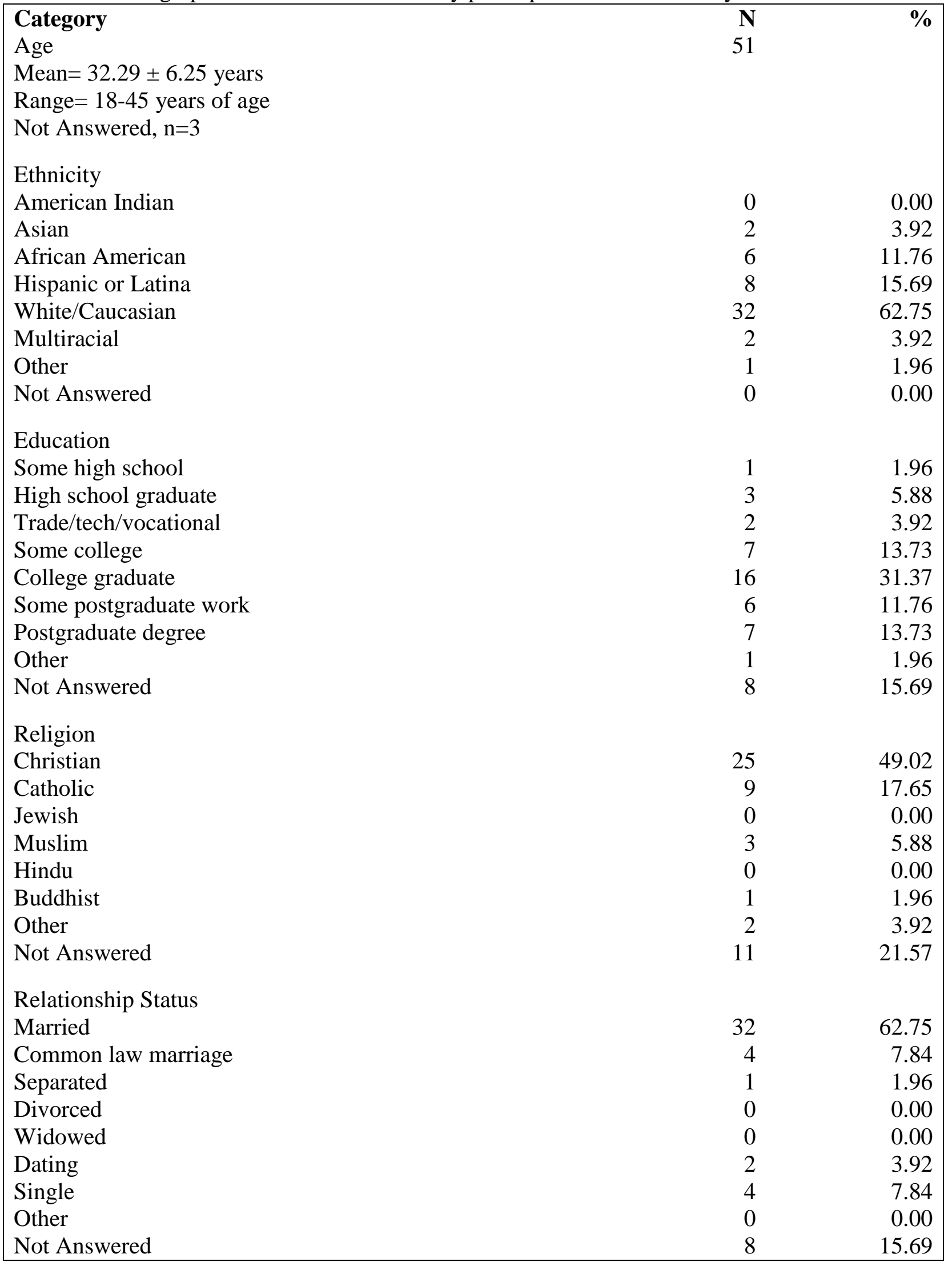


The average self-reported gestational age was $16.77 \pm 3.63$ weeks and ranged from 9 to 23 weeks. For the majority of participants, this was not their first pregnancy $(66.6 \%)$ and most had at least one living child (58.8\%). One participant reported having a past pregnancy with a similar or same anomaly. For the majority of participants $(84.9 \%)$, this was their first time pursuing a termination procedure. Table 2 presents the detailed pregnancy information.

Table 2. Pregnancy information of study participants of initial survey

\begin{tabular}{|c|c|c|}
\hline Category & $\mathbf{N}$ & $\%$ \\
\hline Gestational Age & 51 & \\
\hline \multicolumn{3}{|l|}{ Mean $=16.77 \pm 3.63$ weeks } \\
\hline \multicolumn{3}{|l|}{ Range $=9-23$ weeks } \\
\hline \multicolumn{3}{|l|}{ Not Answered, $\mathrm{n}=0$} \\
\hline \multicolumn{3}{|l|}{ Pregnancy Count } \\
\hline One & 17 & 33.33 \\
\hline Two & 12 & 23.53 \\
\hline Three & 8 & 15.69 \\
\hline Four or more & 14 & 27.45 \\
\hline Not Answered & 0 & 0.00 \\
\hline \multicolumn{3}{|l|}{ Number of Living Children } \\
\hline Zero & 21 & 41.18 \\
\hline One & 18 & 35.29 \\
\hline Two & 7 & 13.73 \\
\hline Three or more & 5 & 9.8 \\
\hline Not Answered & 0 & 0.00 \\
\hline \multicolumn{3}{|c|}{ Same or Similar Anomaly in Previous Pregnancy } \\
\hline Yes & 1 & 1.96 \\
\hline No & 34 & 66.67 \\
\hline Unsure & 2 & 3.92 \\
\hline First pregnancy & 13 & 25.49 \\
\hline Not Answered & 1 & 1.96 \\
\hline \multicolumn{3}{|c|}{ Previous Termination of Pregnancy* } \\
\hline Yes, for fetal/medical reasons & 1 & 1.96 \\
\hline Yes, for social/personal reasons & 7 & 13.73 \\
\hline No & 31 & 60.78 \\
\hline First pregnancy & 13 & 24.49 \\
\hline Not Answered & 0 & 0.00 \\
\hline
\end{tabular}


The majority of participants reported having first discovered the fetal anomaly by a screening tool, specifically ultrasound (66.7\%). Non-invasive prenatal testing (NIPT) was grouped with other blood tests, which was chosen as the initial indication of a fetal anomaly in $29.4 \%$ of participants. Two participants reported that an invasive procedure, such as chronic villus sampling or amniocentesis, had first given them an indication of an anomaly in the pregnancy. Regardless of results from initial testing, 45 participants indicated pursuing additional confirmatory testing and/or imaging. The most common anomaly that participants self-reported was "Down syndrome/Trisomy 21 " followed by brain anomalies. Figure 2 presents the information collected on the anomaly discovered. Of note, 15 participants selected more than one anomaly. Most participants indicated that they were told that the condition was lethal or would result in physical or intellectual impairment. Again, 27 participants selected more than one option regarding the expected implications of the fetal anomaly.

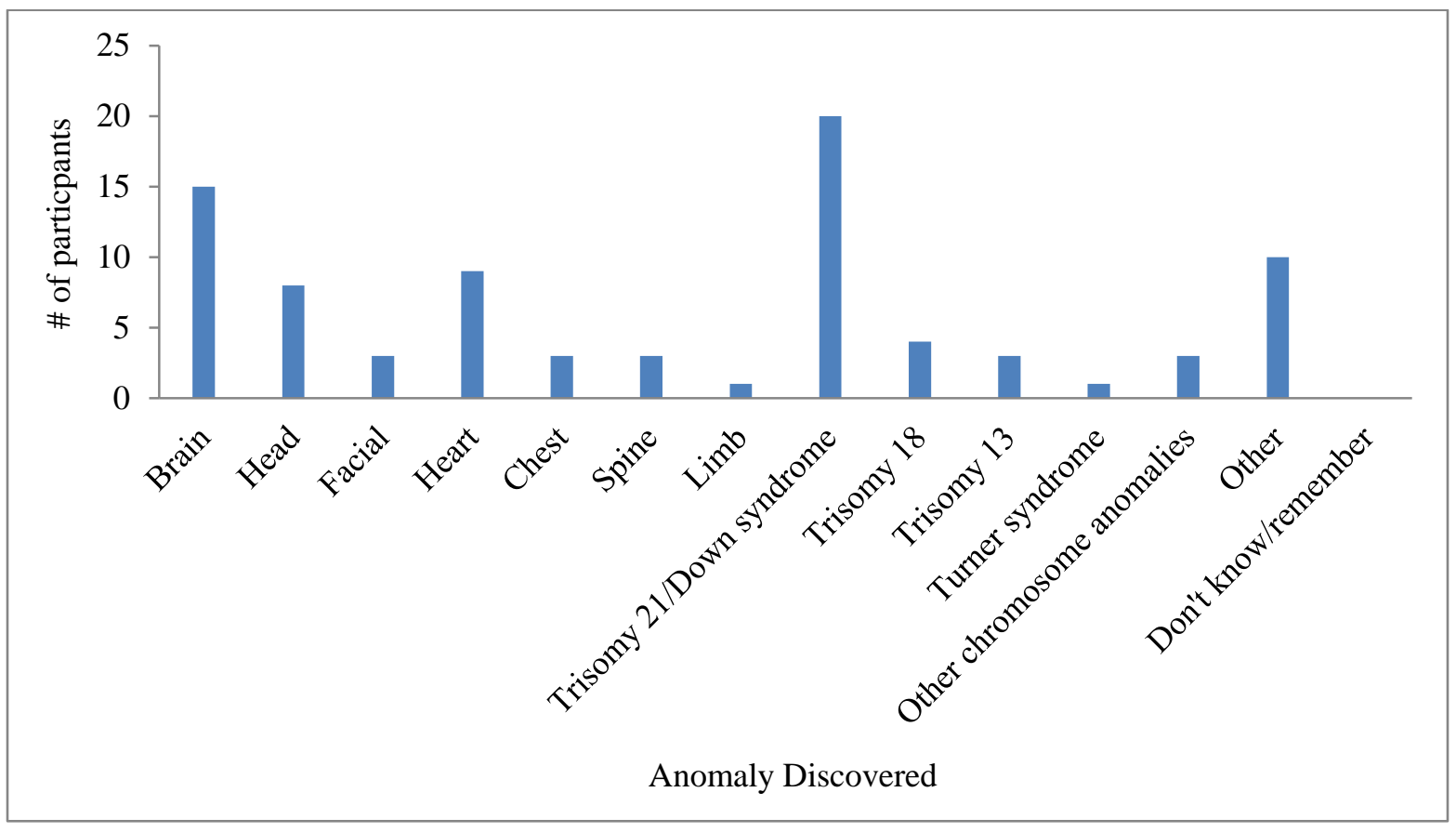

Figure 2. Anomalies identified in the 51 pregnancies, $\mathrm{N}=51$ 
Approximately two thirds $(65.3 \%)$ of respondents reported that the decision to terminate was extremely difficult. A significant association $(\mathrm{p}=0.011)$ was identified between the gestational age and difficulty of the decision, indicating that the further along each participant was in the pregnancy, the harder the decision was to terminate the pregnancy. No significant association was found between the type of fetal anomaly or the expected implications of the fetal anomaly and the level of difficulty of the decision.

When asked about the hardest factor in choosing to end the pregnancy, participants commonly selected the connection to the pregnancy, religious beliefs and doubt about the anomalies identified (Figure 3). Other factors selected included "financial concerns" or "partner and/or other family members in disagreement with the decision to terminate".

Compared to participants who did not select a factor, participants who selected at least one factor were more likely to have considered the decision difficult on some level $(\mathrm{p}=0.016)$.

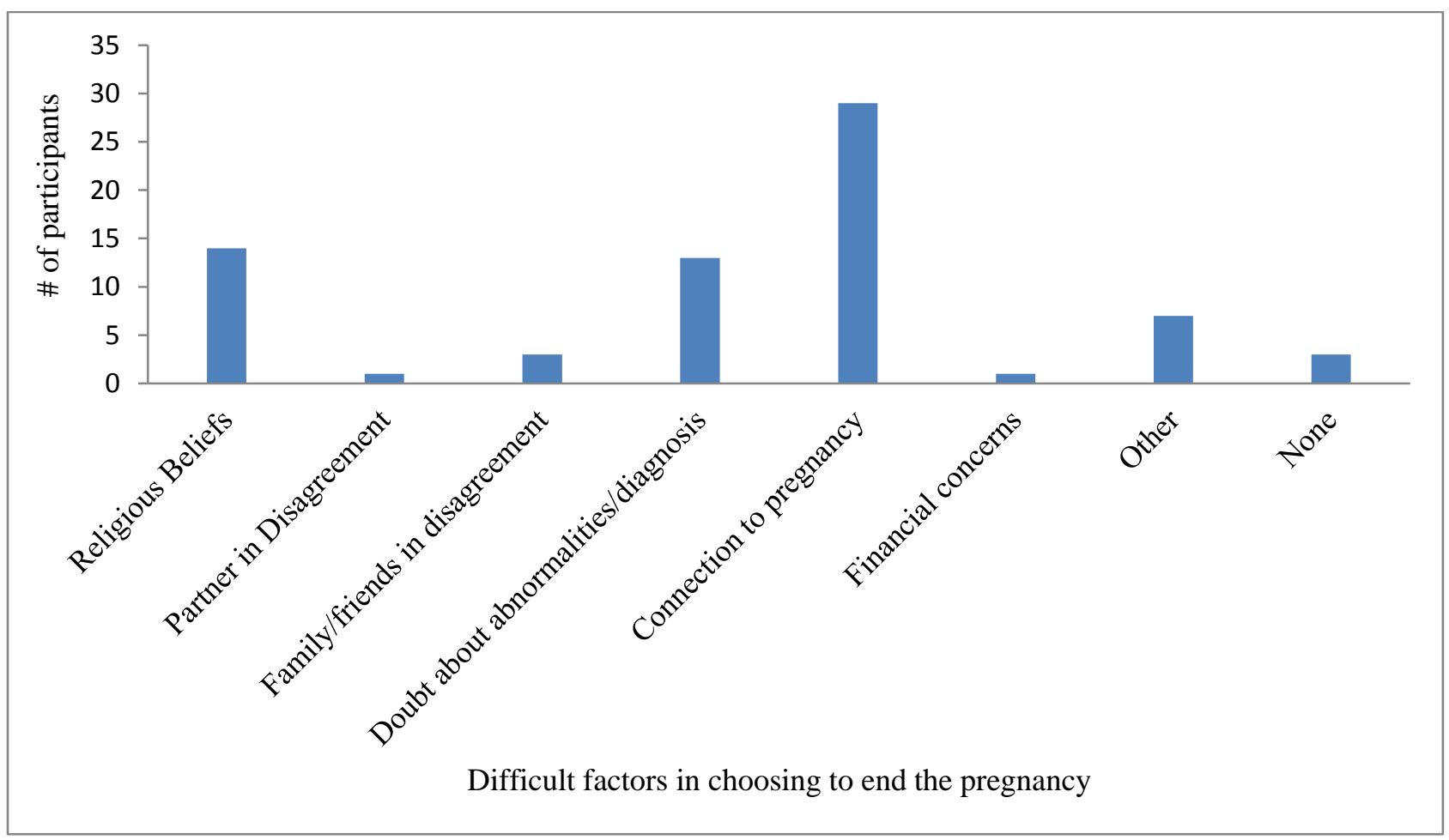

Figure 3. Participant reports on hardest factors in decision to end the pregnancy, $\mathrm{N}=50$ 
All responding participants reported that they had shared the decision to terminate, most commonly with their partner (96.0\%) and immediate family members (88.0\%). Many participants were aware of the support resources available to them and reported their healthcare provider had given these resources to them or that they found them on their own. However, half of the respondents had not contemplated or were unsure of their specific need for support resources. Participants were more likely to have considered their need for support based how difficult they felt the decision was to end the pregnancy $(\mathrm{p}=0.004)$ with the increasing level of difficulty coinciding with an increased consideration of support.

Support from family and friends as well as seeing a genetic counselor were the main support resources that participants anticipated they would use in the future. No participants selected that they expected to utilize video resources though seven participants reported they were aware of such resources. Three respondents (5.9\%) expressed that they would likely seek out a grief counselor, psychiatrist, and/or psychologist. Eight respondents (15.7\%) reported that they did not expect to utilize any support resources following the end of their pregnancy. One of these eight participants expressed that she was too overwhelmed to consider what support she would need or use in the future. When asked about what would influence their decision to utilize support resources, the most common responses were anonymity (34.8\%) or that no factors would impact their utilization (34.8\%; Figure 4). 


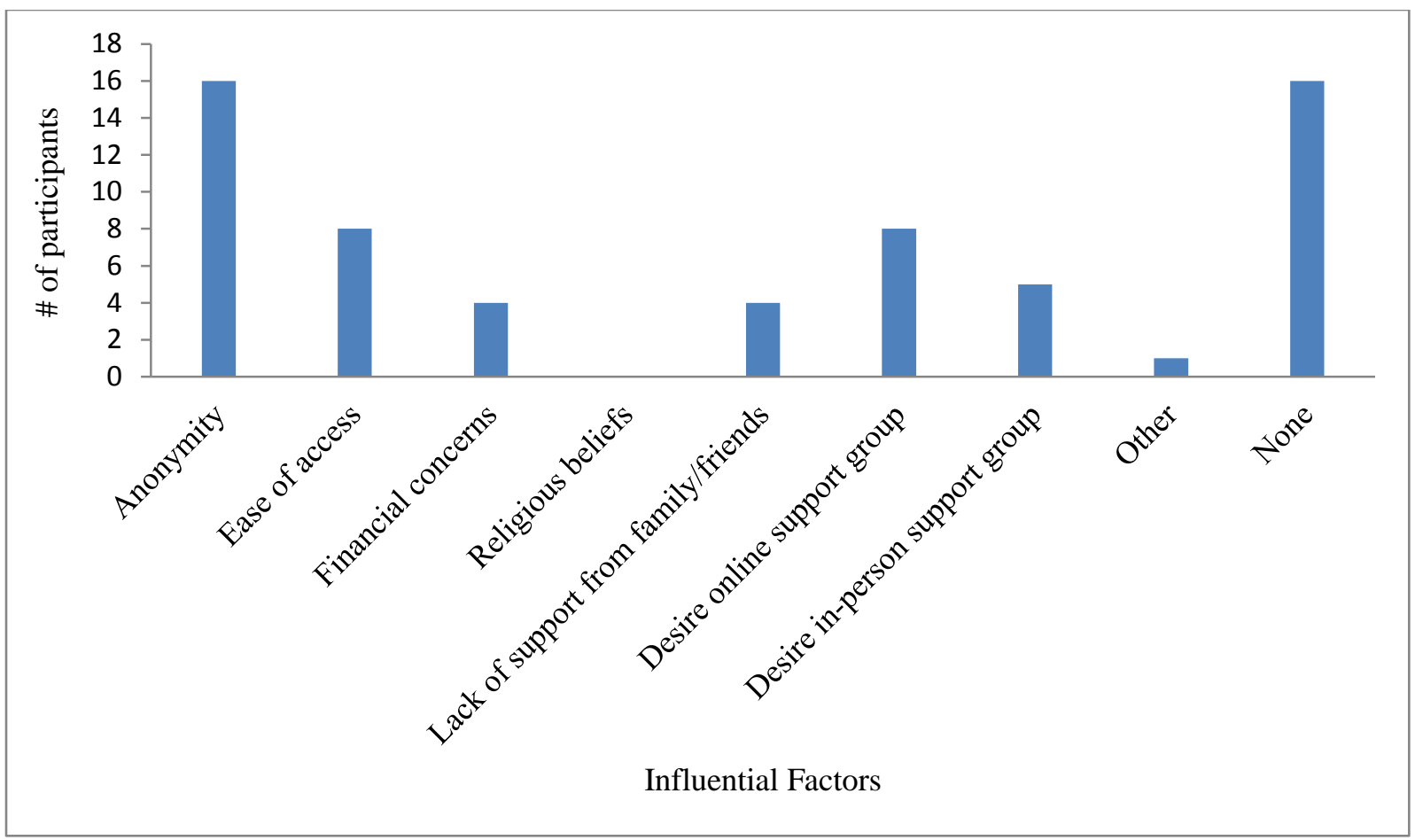

Figure 4. Participant reports on factors that would most influence utilization of a support resource, $\mathrm{N}=50$

When asked if they planned to commemorate the pregnancy in any way, half of respondents indicated that they would not be commemorating their pregnancy in any way. The other half mostly selected that would want to commemorate the pregnancy on their own while two participants indicated that they would like a card from a healthcare provider. No participants chose that they would like to receive a phone call from their healthcare provider(s).

Of the 51 participants, 21 disclosed contact information for the follow-up surveys. Six participants responded to the 6 week follow up survey yielding a response rate of $28.5 \%$. Out of the 17 participants who have been sent the three-month follow-up survey, two participants responded yielding a response rate of approximately $11.8 \%$; four surveys have yet to be sent out. All of our respondents indicated that they were not coping as well as they 
had expected to and that the desire to move on from the pregnancy most prevented them from utilizing support resources. We identified several themes from participant responses in the follow-up surveys, most notably unexpected physiological and psychological consequences of the procedure:

"I experienced moderate mood disruption, i.e. depressed mood, lethargy, and irritability for 4-5 weeks. Additionally, I initially found it difficult to cope with physiological changes I endured as a result of post-pregnancy hormonal changes."

Participants also noted feelings of grief and indicated the need for more resources on how to go through this process:

"It's hard to say [how I am coping]. Frequent crying and depression-it's extremely hard to be around other pregnant women. So many online stories focus on the loss, which is important to relate to. But then you reach a point where you have to cope out in society and not be an emotional mess. It might be nice to know more stories about how people walked through their grief process after it stops being so recent but when it's still so heavy on your heart."

Some participants expressed finding some level of comfort from their religious beliefs

while looking to the future:

"It [the termination] has been the most difficult experience I've ever dealt with. There is nothing in life that prepares you for losing your child, especially one that you had prayed for. I trust completely in God and know wholeheartedly (sp) that $\mathrm{He}$ showed my child and I mercy by giving us the opportunity to let her gain her wings early versus me trying to carry to term and later deal with a greater loss. It is sad, but He and my family are helping us through this and we look forward to trying again soon for a healthy baby."

Of participants who did not disclose contact information for the follow-up surveys, 16 participants reported in the initial survey that it would be too emotional to continue to think of the loss of their pregnancy. Additional reasons for why participants did not disclose contact information included not being comfortable disclosing contact information and not 
wishing to receive emails regarding the follow-up surveys. No participants selected that they were not interested in this topic of research.

\section{Discussion}

The discussion of the availability of support resources typically occurs after a woman has made the decision to end the pregnancy. Healthcare providers, particularly genetic counselors, want to be able to provide support resources to their patients; however, many women are unprepared for the discovery of a fetal anomaly and are more likely focused on making the decision and getting through the procedure and not on their current or future need for support. In our study, $50 \%$ of respondents had not fully contemplated their support needs even though they were well aware of available resources. Additionally, many of the women who declined participation in the follow-up surveys noted doing so as they did not know how they would feel following the procedure.

In times of such distress, many women reported that they expected to be able to rely on the support from family and friends. Unfortunately, previous studies have found that the quality of emotional support from family and friends can vary and fade over time, which can leave these women feeling particularly unsupported and alone in their grief (Lafarge et al., 2013). This declining support may lead to the need for additional resources that patients did not anticipate utilizing at the time of their procedure. This may also cause women to feel like they need to move on from the pregnancy immediately, and thus prevent them from seeking the resources they need.

Given our findings, it does seem that the desire to move on from the pregnancy is more important to women than the factors that would influence utilization of support resources at 
the time of the termination procedure. Our follow-up surveys revealed that many women coped differently than they had expected. One reason for this may be that women categorize their termination with other forms of pregnancy loss to make the loss more bearable:

"I thought it would be a bit easier to get past - like a miscarriage. But I realized after a couple of weeks that it was not something that I would ever fully get over."

By not acknowledging the unique nature of the psychological consequences following a termination for a fetal anomaly, these women may experience delayed grief. The concept is defined as grief that may be postponed or suppressed, rather than experienced fully at the time of the loss. However, a later event may trigger an intense reaction. This reaction may occur within the first few months to years following the procedure and could be triggered by a number of different events, including interacting with other pregnant women, the anniversary of the termination procedure, the anticipated due date, and becoming or failing to become pregnant again (Lafarge et al., 2013; White-van Mourik et al., 1992). This further demonstrates the need to develop a support resource that would be generally applicable as women may seek support at different timepoints in the recovery process.

This study determined that the difficulty of decision was directly proportional to the gestational age at which the decision was made. Unfortunately, we were only able to survey women pursuing the option of termination prior to 22 weeks gestation. The Texas House Bill 2 was signed into law on July 18, 2013 and put into effect on October 29, 2013. This bill prohibits terminations past 22 weeks gestation, though exceptions can be made if the fetal anomaly is considered to be lethal or "severe" or if continuing the pregnancy would be severely detrimental to the mother's health. 
There are several states that do allow termination procedures past 22 weeks gestation and well into the third trimester. These late-term procedures are thought to account for less than $1 \%$ of the total number of procedures in the United States (Pazol et al., 2013). Given our findings, we would expect that the decision to end the pregnancy in the third trimester of pregnancy would be even more difficult. The grief response of women in these situations may also be more immediate and intense. Future studies may find that the support needs of women pursuing a termination for a fetal anomaly in the third trimester may be different from our study population.

An additional limitation of this study is the lack of detailed information on those who declined participation in the study as well as those who did not respond to the follow-up surveys. This may have caused a selection bias as the psychological response for individuals who declined participation may be different than those who participated. Our population also mainly consisted of highly-educated women of probable higher socioeconomic status, though socioeconomic status was not specifically assessed. It is possible that women of lower socioeconomic status may differ in their pre-existing support systems and their need for resources. However, we question if this is truly a limitation or whether it is representative of the population that is able to pursue termination at later gestational ages. Though the occurrence of a fetal anomaly does not depend on socioeconomic status, it is those of higher status that are able to afford the termination procedure.

Another limitation of this study is its small sample size, both in the initial and especially in the follow-up surveys, which prevented larger statistical analysis. Due to limitations imposed by the IRB on what data could be collected from the patients or the 
clinic, we were unable to assess how many potentially eligible patients were seen during the study period. However, based on anecdotal evidence of patients seen per week we were able estimate the response rate of approximately $62.2 \%$ for this study. Therefore, the low sample size is probably a reflection of a low frequency of eligible patients seen in the specific clinic rather than a low uptake of the questionnaire.

The main strength of our study is its longitudinal design, beginning with the initial date of the termination procedure. To our knowledge, this is a novel design and allowed us to gain insight into the desires of this population at a critical timepoint. By attempting to sample all eligible participants from a private clinic, we were able to collect different viewpoints, including those who were not interested in support options. For those who were interested in utilizing resources, many had still not given thought about how they would cope following the procedure. Furthermore, based on our finding of unexpected difficulty in coping among patients who did respond to the follow-up survey, it is possible that, from a clinical and counseling point of view, patients who initially demonstrated no interest in support options may be severely underestimating the impact that termination of pregnancy for a fetal anomaly would have in the weeks and months following the procedure. However, it would be difficult to assess that without a more thorough follow-up of all patients.

The data collected can impact current clinical care of women pursuing a termination for a fetal anomaly. Healthcare providers should consider setting up a plan with these patients for follow-up with the understanding that initial desires for support may not truly represent long-term needs. It may be beneficial for healthcare providers to discuss the wide range of emotions that can be felt after the procedure and that resources are available at any time. Information concerning these support resources should be sent to the primary and/or 
referring provider as the patient may be more in touch with these individuals following the end of the pregnancy. A routine referral to a grief counselor and/or psychologist should also be considered, as many are unprepared for the level of grief that may follow the termination event.

It is also important to acknowledge that many women feel vulnerable following the termination procedure and want to avoid painful reminders of their pregnancies as they begin the recovery process, as was the case for many women who declined participation in our follow-up surveys. Many healthcare professionals want to re-contact patients in the follow-up period to provide support, but this need for distance must also be respected. Contact with these women in the immediate follow-up period should be limited unless a plan has been mutually agreed upon before the termination procedure.

Our study also indicated the need for additional support resources to be developed to meet this population's needs and desires. Given that the factors of anonymity, ease of access, and the opportunity to meet other women in a similar situation were the most appealing to women considering utilization of a support resource, a private online support group would seem to be the best option. Online support groups for women terminating for a fetal anomaly do currently exist, but it remains undetermined if they are fully meeting the needs and desires of this population. Research in other patient populations has shown that online support groups can offer users a sense of control that they may not have with face-toface conversations and can improve self-expression and social support; however, there are potential disadvantages, including sharing inaccurate information and creating an unhealthy obsession of the event (Malik et al., 2008). In order for a support group in this population to truly be successful, a moderator within the medical profession may be needed to recognize 
any maladaptive coping mechanisms and offer personalized referrals.

A further longitudinal study following this patient population is needed, as it still remains unknown of when these patients start to seek out support resources. Timing seems to be an important factor and such information may further help healthcare professionals understand when would be the best time to discuss the availability of support resources. We hope that the insight gained from our study helps better care for women in these situations and serves as a starting point for the development of new resources for this population. 
Appendix A: Letter of Invitation

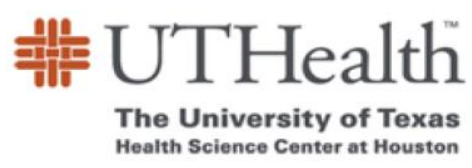

Dear Potential Participant,

My name is Aarti Ramdaney and I am a graduate student at the University of Texas Health Sciences Center at Houston. For my thesis project, I am conducting a research study about the support and follow-up that is desired by women undergoing a termination of pregnancy procedure for a fetal anomaly. I would like to invite you to participate in this research study, by completing the attached brief questionnaire. This information will be important for healthcare professionals to gain insight into the needs of patients who will face similar experiences.

The questionnaire will take about five to ten minutes to complete. If you choose to participate, please answer the questions honestly and to the best of your ability. The questions will ask about support resources you may have been offered; as well as if there are any resources you wish had been offered to you. There are no wrong answers; and you may skip any questions you do not want to answer. All questionnaires will remain anonymous. Participation is voluntary and you may choose not to take part in responding to the questionnaire(s).

At the end of this letter, you will be asked to provide your e-mail or mailing address so that I can send you two follow-up surveys (one in 6 weeks and one 3 months after today). The follow up surveys will ask similar questions to this survey. If you would like to take part in the follow-up part of the study; once you have completed the survey, please place the contact page and the survey into the drop box, located at the front desk of the clinic. Please be sure that you place both documents into the drop box separately so that your responses can remain anonymous.

You will not be personally identified in any reports or publications that may result from this study. Any personal information about you that is gathered during this study will remain confidential to every extent of the law. A special code number will be used to identify you in the study and only the investigator will know your name. There is possible risk of breach of confidentiality; however, all information that you provide for this study, will be kept confidential. Your e-mail/mailing address will remain separate from your survey responses so that your responses to the follow-up surveys remain anonymous.

You will not be paid to take part in this study.

Although you may not receive any direct benefit, the information you provide may help in the development of additional support resources that others may use in the future. If you desire support and have not yet received any, you may consider visiting www.aheartbreakingchoice.com.

Thank you for taking the time to help me with this project. The information you provide will hopefully lead to additional, useful information that will help healthcare professionals offer support to patients in similar situations in the future. If you would like additional information or have further questions or concerns, please feel free to contact me at the email address listed below. Thank you again for your participation.

Sincerely,

Aarti Ramdaney

Contact email address: Aarti.Ramdaney@uth.tmc.edu

CPHS Statement: The study has been reviewed by the Committee for the Protection of Human Subjects (CPHS) of the University of Texas Health Science Center at Houston. For any questions about research subject's rights, or to report a research related injury call the CPHS at (713) 500-7943. 


\section{Contact Page}

Thank you for your participation in this survey. If you are willing to also take part in the follow-up surveys, please provide your email address so that I may send you the surveys. If you do not have access to email and would like to participate, you can also provide your mailing address.

Again, your contact information will be kept separate from your survey responses so that your responses remain anonymous. I also ask that you provide today's date so that I can time when to send the follow-up surveys to you. Thank you again for your participation.

(Please provide one of the following contact methods and return this form in the drop box. Please do not attach this form to the survey.)

E-mail:

Mailing Address:

Today's Date:

If you wish not to participate in the follow-up surveys, please indicate the reason(s) for your decision below. Check all that apply.

I don't feel comfortable providing my email/mailing address

I don't want to receive emails about a follow-up survey

I am not interested in the topic of this research

It is too much emotionally to continue to think about the loss of my pregnancy

I don't know how I will feel in 6 weeks and 3 months and I don't want to be caught off guard by an email

I don't like participating in research in general

Other: 


\section{Appendix B: Initial Survey}

Please answer the following questions based on your thoughts. There are no wrong answers.

1. What is your Age:

2. What is your race/ethnicity?

$\square$ American Indian

$\square$ Asian

$\square$ African American

- Hispanic or Latina

$\checkmark$ White/Caucasian

Multiracial

$\square$ Other
3. What is your highest level of education completed?

$\square$ Some high school

$\square$ High school graduate

$\square$ Some college

$\square$ Trade/tech/vocational

$\square$ College graduate

$\square$ Some postgraduate work

$\square$ Postgraduate degree

$\square$ Other
4. What is your religion?

$\square$ Christian

$\square$ Catholic

$\square$ Jewish

$\square$ Muslim

$\square$ Hindu

$\square$ Buddhist

$\square$ Other
5. What is your marital status?

$\square$ Married

$\square$ Common law marriage

$\square$ Separated

$\square$ Divorced

$\square$ Widowed

$\square$ Dating

$\square$ Single

6. How far along in the pregnancy are you? weeks

7. Including this pregnancy, how many times have you been pregnant?
$\square 1$
$\square 2$
$\square 3$
$\square 4$ or more

8. How many living children do you have?
$\square 0$
$\square 1$
$\square 2$
$\square 3$ or more

9. If this is not your first pregnancy, have you had a past pregnancy that had the same or similar abnormality?
$\square$ Yes
$\square$ No
$\square$ This is my first pregnancy

10. Have you had a termination of pregnancy previously?

$\square$ Yes, for fetal/medical reasons $\square$ Yes, for personal/social reasons $\square$ No $\square$ This is my first pregnancy

11. How did you first learn that there was an abnormality in the pregnancy?
$\square$ Ultrasound
$\square$ Blood test or NIPT
CVS/Amniocentesis
$\square$ Other:

12. Did you do any additional testing? Check all that apply
$\square$ CVS/Amniocentesis
NIPT or blood tests
$\square$ Other:
Ultrasound

13. What kind of abnormality was discovered? Check all that apply

$\begin{array}{lll}\square \text { Brain } & \square \text { Spine } & \square \text { Turner Syndrome/45, X } \\ \square \text { Head } & \square \text { Limb } & \square \text { Other chromosome abnormality } \\ \square \text { Facial } & \square \text { Down Syndrome/Trisomy 21 } & \square \text { Other: } \\ \square \text { Heart } & \square \text { Trisomy 18 } & \square \text { I don't know/remember } \\ \square \text { Chest } & \square \text { Trisomy 13 } & \end{array}$

14. What were you told about the anomaly discovered? Check all that apply.

$\square$ Pregnancy or infant would not survive $\square$ Other:

$\square$ Infant would have severe physical impairment $\quad \square$ Cannot remember what I was told about anomaly

$\square$ Infant would have severe intellectual/mental discovered impairment

$\square$ Infant would develop disease later on in life

$\square$ Was not told anything about anomaly discovered

15. How hard was the decision to end the pregnancy?
$\square$ Extremely
$\square$ Moderately
$\square$ Somewhat $\quad \square$ Not as difficult as expected

PLEASE TURN OVER TO COMPLETE SURVEY 
16. With whom have you shared the decision to end the pregnancy? Check all that apply.
Partner
$\square$ Extended family members
$\square$ Other:
Immediate family members
$\square$ Friends
$\square$ I have not shared this decision

17. What has been the hardest part in deciding to end the pregnancy? Please check only one.
Religious beliefs
Partner in disagreement of decision
$\square$ Connection with pregnancy
Other family members or friends in
$\square$ Financial concerns
disagreement of decision
$\square$ Doubt about abnormalities/diagnosis
$\square$ Other:
$\square$ None of the above were difficult factors in choosing to end the pregnancy

18. Have you considered the need for any support or follow-up for yourself following the end of pregnancy?
$\square$ Yes
$\square$ No
$\square$ Unsure

19. What support services for ending a pregnancy are you aware of? Check all that apply.

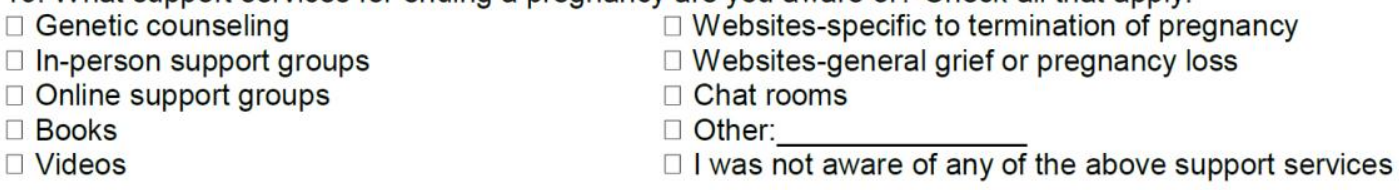

20. How did you find this available support? Check all that apply.

$\begin{array}{ll}\square \text { Healthcare professional } & \square \text { Religious leader } \\ \square \text { Found on my own } & \square \text { Other: } \\ \square \text { Family members } & \square \text { Did not find support }\end{array}$

21. What support services do you anticipate using following the end of the pregnancy? Check all that apply.

$\begin{array}{ll}\square \text { Genetic counseling } & \square \text { Websites-specific to termination of pregnancy } \\ \square \text { In-person support groups } & \square \text { Websites-general grief or pregnancy loss } \\ \square \text { Online support groups } & \square \text { Support from family and friends } \\ \square \text { Books } & \square \text { Other: } \\ \square \text { Videos } & \square \text { None of the above }\end{array}$

22. What factors would influence your decision to participate in a support system following the end of the pregnancy? Check all that apply.

Want to remain anonymous

$\square$ Ease of access/convenience

$\square$ Financial concerns

$\neg$ Religious beliefs

$\checkmark$ Lack of support from family/friends

$\square$ Want to meet other women in a similar situation online

$\square$ Want to meet other women in a similar situation in-person

$\square$ Other:

$\square$ None of the above would influence my decision

23. What additional support, if any, do you wish had been offered to you at this time?

24 . Would you want a way to commemorate this pregnancy?

$\square$ Yes, receiving a call the week of my due date from a healthcare professional

$\checkmark$ Yes, receiving a card in the mail from a healthcare professional

$\square$ Yes, will commemorate pregnancy on own

$\square$ Yes, other:

No, I do not want a way to commemorate this pregnancy

25. Is there additional information you would like us to know to better offer support to other women in a similar situation? 
Appendix C: Follow-Up Surveys

FOLLOW-UP SURVEY

Demographics

1. What is your age?

2. What is your race/ethnicity?
$\square$ American Indian
$\square$ Asian
$\square$ African American
$\square$ Hispanic or Latina
$\square$ White/Caucasian
$\square$ Multiracial
$\square$ Other

3. What is your highest level of education completed?
$\square$ Some high school
$\square$ High school graduate
$\square$ Some college
$\square$ Trade/tech/vocational
$\square$ College graduate
$\square$ Some postgraduate work
$\square$ Postgraduate degree
$\square$ Other

4. What is your religion?
$\square$ Christian
$\square$ Catholic
$\square$ Jewish
$\square$ Muslim
$\square$ Hindu
$\square$ Buddhist
$\square$ Other

5. What is your marital status?

$\square$ Married
$\square$ Common law marriage
$\square$ Separated
$\square$ Divorced
$\square$ Widowed
$\square$ Dating
$\square$ Single
$\square$ Other




\section{FOLLOW-UP SURVEY}

\section{Pregnancy Information}

6. How far along were you when the pregnancy ended? : weeks

7. Including the pregnancy that ended recently how many times have you been pregnant?
$\square 1$
$\square 2$
$\square 3$
$\square 4$ or more

8. How many living children do you have?
$\square 0$
$\square 1$
$\square 2$
$\square 3$ or more

9. Prior to this most recent pregnancy, have you had a past pregnancy that had the same or similar abnormality?
$\square$ Yes
$\square$ No
$\square$ I have only been pregnant once

10. Prior to this most recent pregnancy, have you had a termination of pregnancy?

$\square$ Yes, for fetal/medical reasons

$\square$ Yes, for personal/social reasons

$\square$ No

$\square$ I have only been pregnant once

11. How did you first learn that there was an abnormality in your recent pregnancy?

$\square$ Ultrasound

$\square$ CVS/Amniocentesis

$\checkmark$ Blood test or NIPT

$\square$ Other:

12. Did you do any additional testing? Check all that apply

$\square$ CVS/Amniocentesis

$\square$ NIPT or blood tests

$\square$ Ultrasound

$\square$ Other:

$\square$ No additional testing 
FOLLOW-UP SURVEY

13. What kind of abnormality was discovered? Check all that apply.
$\square$ Brain
$\square$ Head
$\square$ Down Syndrome/Trisomy 21
Facial
Trisomy 18
Heart
Trisomy 13
Chest
Turner Syndrome/45,X
$\checkmark$ Spine
Other chromosome abnormality
Other:
Limb
I don't know/remember

14. What were you told about the anomaly discovered? Check all that apply.

$\square$ Pregnancy or infant would not survive

$\square$ Infant would have severe physical impairment

$\square$ Infant would have severe intellectual/mental impairment

$\square$ Infant would develop disease later on in life

$\square$ Other:

Cannot remember what I was told about anomaly discovered

$\square$ Was not told anything about anomaly discovered

15. How hard was the decision to end the pregnancy?
$\square$ Extremely
Moderately
$\square$ Somewhat
$\square$ Not as difficult as expected

16. With whom have you shared the decision to end the pregnancy? Check all that apply.
Partner/spouse
$\square$ Immediate family members
$\square$ Extended family members
Friends
Other:

$\square$ I have not shared this decision

17. What was the hardest part in deciding to end the pregnancy? Please check only one response.

$\square$ Religious beliefs

Partner in disagreement of decision

$\checkmark$ Other family members or friends in disagreement of decision

Doubt about abnormalities/diagnosis

$\square$ Connection with pregnancy

Financial concerns

Other:

$\square$ None of the above were difficult factors in choosing to end the pregnancy 
FOLLOW-UP SURVEY

\section{Support}

18. Were you interested in support options when the discussion of ending your recent pregnancy first came up?

$\square$ Yes

$\square$ No

$\square$ Unsure

19. What support services have you utilized since your recent pregnancy ended?

$\square$ Genetic counseling

$\square$ In-person support groups

$\square$ Online support groups

$\square$ Books

$\square$ Videos

Websites-specific to termination of pregnancy

$\square$ Websites-general grief or pregnancy loss

$\checkmark$ Support from family and friends

Other:

$\checkmark$ None

20. What support options were you interested in but never participated in?

$\square$ Genetic counseling

In-person support groups

Online support groups

Books

$\square$ Videos

$\square$ Websites-specific to termination of pregnancy

$\square$ Websites-general grief or pregnancy loss

$\square$ Other:

None

21. What factor(s) influenced your decision not to participate in certain support options? Check all that apply.

$\square$ Wanted to remain anonymous

$\square$ Difficulty of access/not convenient

Financial concerns

Religious beliefs

Felt enough support from family/friends/other services

Lack of encouragement to seek support from family/friends

Wanted to move on from most recent pregnancy

Other:

$\square$ None of the above have influenced my participation

$\square$ I have participated in a support service to help cope with my pregnancy loss 
FOLLOW-UP SURVEY

22. Was it difficult to find support options?

$\square$ Yes

$\square$ No

$\square$ Unsure

$\square \mathrm{I}$ have not tried to find any support services

23. What is your opinion on the current support services available? Check all that apply

$\square$ Meet my needs

$\square$ Hard to find

$\square$ Not specific to my situation

$\square$ Do not meet my needs

Other:

$\square$ No opinion on current support services

24. What support options do you wish were available?

25. Has there been support that you have been offered or utilized that was not helpful or that was unwelcome? What were they?

26. How do you feel like your partner/spouse is coping with the end of the pregnancy?

$\square$ Better than I am

Same as I am

$\square$ Worse than I am

$\square$ Not sure

Other:

Partner is no longer involved

$\square$ Partner was never involved with pregnancy 
FOLLOW-UP SURVEY

27. What factors have made it harder to cope with the end of your recent pregnancy? Check all that apply

$\square$ Religious beliefs

$\square$ Partner in disagreement with decision

Family or friends in disagreement with decision

Doubt about abnormalities/diagnosis

$\checkmark$ Connection with pregnancy

Other:

$\checkmark$ None of the above have been difficult factors

28. Have you been coping with the end of your recent pregnancy as you thought you would? Please tell us more about how you feel you are doing, along with anything else you would like us to know about your experiences.

If you desire support and have not yet received any, you may consider visiting www.aheartbreakingchoice.com. If you are experiencing suicidal or harmful thoughts, please call the 24 hour National Suicide Prevention Lifeline at 1-800-273-8255 to talk to someone, or visit their website at http://www.suicidepreventionlifeline.org/ 


\section{References}

Bryar, S. H. (1997). One day you're pregnant and one day you're not: pregnancy interruption for fetal anomalies. Journal of obstetric, gynecologic, and neonatal nursing: JOGNN / NAACOG, 26(5), 559-566.

Bulas, D. (2012). Executive summary: advances in fetal and neonatal imaging. Pediatric radiology, 42 Suppl 1, S3-4. doi:10.1007/s00247-011-2245-6

Elder, S. H., \& Laurence, K. M. (1991). The impact of supportive intervention after second trimester termination of pregnancy for fetal abnormality. Prenatal diagnosis, 11(1), $47-54$.

Finer, L. B., \& Kost, K. (2011). Unintended pregnancy rates at the state level. Perspectives on sexual and reproductive health, 43(2), 78-87. doi:10.1363/4307811

Hunt, K., France, E., Ziebland, S., Field, K., \& Wyke, S. (2009). “My brain couldn”t move from planning a birth to planning a funeral': a qualitative study of parents' experiences of decisions after ending a pregnancy for fetal abnormality. International journal of nursing studies, 46(8), 1111-1121. doi:10.1016/j.ijnurstu.2008.12.004

Kersting, A, Dorsch, M., Kreulich, C., Reutemann, M., Ohrmann, P., Baez, E., \& Arolt, V. (2005). Trauma and grief 2-7 years after termination of pregnancy because of fetal anomalies--a pilot study. Journal of psychosomatic obstetrics and gynaecology, 26(1), 9-14.

Kersting, Anette, Kroker, K., Steinhard, J., Hoernig-Franz, I., Wesselmann, U., Luedorff, K., Ohrmann, P., Arolt, V., \& Suslow, T. (2009). Psychological impact on women after second and third trimester termination of pregnancy due to fetal anomalies versus women after preterm birth--a 14-month follow up study. Archives of 
women's mental health, 12(4), 193-201. doi:10.1007/s00737-009-0063-8

Kersting, Anette, \& Wagner, B. (2012). Complicated grief after perinatal loss. Dialogues in clinical neuroscience, 14(2), 187-194.

Kolker, A., \& Burke, B. M. (1993). Grieving the anted child: ramifications of abortion after prenatal diagnosis of abnormality. Health care for women international, 14(6), 513526. doi:10.1080/07399339309516081

Korenromp Marijke J, Iedema-Kuiper, H.R., van Spijker, H.G., Christiaens, G.C.M.L., \& Bergsma, J. 1992. Termination of pregnancy on genetic grounds; coping with grieving. J Psychosom Obstet Gynaecol 13: 93-105.

Korenromp, Marijke J, Christiaens, G. C. M. L., van den Bout, J., Mulder, E. J. H., Hunfeld, J. A. M., Bilardo, C. M., Offermans, J.P.M, \& Visser, G. H. A. (2005). Long-term psychological consequences of pregnancy termination for fetal abnormality: a crosssectional study. Prenatal diagnosis, 25(3), 253-260. doi:10.1002/pd.1127

Korenromp, Marijke J, Page-Christiaens, G. C. M. L., van den Bout, J., Mulder, E. J. H., Hunfeld, J. A. M., Bilardo, C. M., Offermans, J.P.M, \& Visser, G. H. A. (2005). Psychological consequences of termination of pregnancy for fetal anomaly: similarities and differences between partners. Prenatal diagnosis, 25(13), 1226-1233. doi:10.1002/pd.1307

Korenromp, Marijke J, Page-Christiaens, G. C. M. L., van den Bout, J., Mulder, E. J. H., \& Visser, G. H. A. (2009). Adjustment to termination of pregnancy for fetal anomaly: a longitudinal study in women at 4, 8, and 16 months. American journal of obstetrics and gynecology, 201(2), 160.e1-7. doi:10.1016/j.ajog.2009.04.007 
Lafarge, C., Mitchell, K., \& Fox, P. (2013). Women's experiences of coping with pregnancy termination for fetal abnormality. Qualitative health research, 23(7), 924-936. doi:10.1177/1049732313484198

Mansfield, C., Hopfer, S., \& Marteau, T. M. (1999). Termination rates after prenatal diagnosis of Down syndrome, spina bifida, anencephaly, and Turner and Klinefelter syndromes: a systematic literature review. European Concerted Action: DADA (Decision-making After the Diagnosis of a fetal Abnormality). Prenatal diagnosis, 19(9), 808-812.

Malik, S. H., \& Coulson, N. S. (2008). Computer-mediated infertility support groups: an exploratory study of online experiences. Patient education and counseling, 73(1), 105-113. doi:10.1016/j.pec.2008.05.024

Pazol, K., Creanga, A. A., Burley, K. D., Hayes, B., Jamieson, D. J., \& Centers for Disease Control and Prevention (CDC). (2013). Abortion surveillance - United States, 2010. Morbidity and mortality weekly report. Surveillance summaries (Washington, D.C.: 2002), 62(8), 1-44.

Robson, F.M. (2002). "Yes! — A chance to tell my side of the story": A case study of a male partner of a women undergoing termination of pregnancy for a fetal abnormality. Journal of health psychology, 7(2), 183-193. doi:10.1177/1539105302007002457

Salvesen, K. A., Oyen, L., Schmidt, N., Malt, U. F., \& Eik-Nes, S. H. (1997). Comparison of long-term psychological responses of women after pregnancy termination due to fetal anomalies and after perinatal loss. Ultrasound in obstetrics \& gynecology: the official journal of the International Society of Ultrasound in Obstetrics and Gynecology, 9(2), 80-85. doi:10.1046/j.1469-0705.1997.09020080.x 
Schechtman, K. B., Gray, D. L., Baty, J. D., \& Rothman, S. M. (2002). Decision-making for termination of pregnancies with fetal anomalies: analysis of 53,000 pregnancies. Obstetrics and gynecology, 99(2), 216-222.

Souka, A. P., Michalitsi, V. D., Skentou, H., Euripioti, H., Papadopoulos, G. K., Kassanos, D., Messinis, I.E., \& Salamalekis, E. E. (2010). Attitudes of pregnant women regarding termination of pregnancy for fetal abnormality. Prenatal diagnosis, 30(10), 977-980. doi:10.1002/pd.2600

White-van Mourik, M. C., Connor, J. M., \& Ferguson-Smith, M. A. (1992). The psychosocial sequelae of a second-trimester termination of pregnancy for fetal abnormality. Prenatal diagnosis, 12(3), 189-204. 


\section{Vita}

Aarti Ramdaney was born in Queens, New York on January 8, 1990, the daughter of Gita Ramdaney and Vic Ramdaney. After completing her work at Bedford High School, Bedford, Pennsylvania in 2008, she entered Cedar Crest College in Allentown, Pennsylvania. She received the degree of Bachelor of Science with a major in genetic engineering and minors in chemistry, mathematics, and psychology from Cedar Crest in May, 2012. In August of 2012, she entered The University of Texas Health Science Center at Houston Graduate School of Biomedical Sciences.

Permanent address:

2121 Hepburn Street, Apt 721

Houston, TX 77054 